\title{
The valvula cerebelli of the spiny eel, Macrognathus aculeatus, receives primary lateral-line afferents from the rostrum of the upper jaw
}

\author{
Mario F. Wullimann *, Michael H. Hofmann, and Dietrich L. Meyer \\ Abteilung für Neuroanatomie der Universität, Zentrum Anatomie, W-3400 Göttingen, Federal Republic of Germany \\ Accepted June 20, 1991
}

Summary. In the spiny eel, Macrognathus aculeatus, anterodorsal and (to a lesser degree) anteroventral lateralline nerves project massively to the granular layer of the valvula cerebelli, throughout its rostrocaudal extent. The posterior lateral-line nerve terminates in the corpus cerebelli. Thus, valvula and corpus cerebelli are supplied with mechanosensory input of different peripheral origins. An analysis of the taxonomic distribution of experimentally determined primary lateral-line input to the three parts of the teleostean cerebellum reveals that the eminentia granularis always receives such input, and that the corpus cerebelli is the recipient of primary lateral-line input in many teleosts. The valvula, however, receives primary lateral-line afferents in only two examined species. In $M$. aculeatus, the massive lateral-line input to the valvula probably originates in mechanoreceptors located in the elongated rostrum of the upper jaw, a characteristic feature of mastacembeloid fishes. This projection to the valvula may therefore represent a unique specialization that arose with the evolution of the peculiar rostrum.

Key words: Cerebellum - Valvula - Lateral-line system - Mechanoreception - Macrognathus aculeatus (Teleostei)

The rostral portion of the cerebellum in ray-finned fishes (actinopterygians) is termed the valvula cerebelli. It extends into the mesencephalic ventricle. Since the valvula is exclusively present in actinopterygians (Larsell 1967; Nieuwenhuys 1967), it can be considered a shared derived character (synapomorphy) of these fishes, as suggested by Herrick (1924) at the beginning of this century. Recently, Wullimann and Northcutt $(1988,1989)$ corroborated this interpretation with a comparison of connec-

\footnotetext{
* Present address and address for offprint requests: Institut für Hirnforschung, Universität Bremen, FB 2, Postfach 3304 40, W2800 Bremen 33, Federal Republic of Germany
}

tional and electrophysiological data from ray-finned and cartilaginous fishes.

In some of the classical descriptive literature (Addison 1923; Herrick 1924; Pearson 1936b), the development of the valvula has been correlated with that of the lateral-line nerves. In particular, primary lateral-line input has been shown, using histological material, to reach the valvula in several teleost species. As in the case of the primary projections of the octaval nerve to the vestibulo-lateral lobe of the cerebellum in all gnathostome vertebrates, the lateral-line input to the valvula has been interpreted as ancestral for teleosts (Addison 1923; Pearson 1936b).

However, modern tracer studies (degeneration and horseradish peroxidase labeling) of primary lateral-line projections, involving more than a dozen teleost species (see Table 1), indicate that (except for the black molly, Mollienesia; Claas and Münz 1981) such projections to the valvula are absent. In the present horseradish peroxidase study, we have examined the primary lateral-line projections to the valvula cerebelli in the spiny eel $\mathrm{Mac}$ rognathus aculeatus, and we have reviewed all studies of experimentally determined primary lateral-line projections to the three different parts of the teleostean cerebellum. For the sake of completeness, a short report is also given on the trigeminal and facial components and the lateral-line projections to the medial octavolateralis nucleus, which were revealed by the labeling of the various nerve trunks of $M$. aculeatus.

\section{Materials and methods}

\section{Horseradish peroxidase (HRP) labeling}

Sixteen specimens of Macrognathus aculeatus $(5-15 \mathrm{~cm})$ were used for transganglionic horseradish peroxidase labeling of various nerve trunks containing lateral-line fibers. The fish were deeply anesthetized with tricaine methanesulfonate (MS 222, Sigma, Deisenhofen, FRG). A $30 \%$ HRP solution (Boehringer, Mannheim, FRG), containing $1 \%$ dimethylsulfoxide and $1 \%$ lysolecithin, was made and allowed to dry. Then, solid particles of this material 
Table 1. Lateral-line nerve projections to the cerebellum in teleosts. ALLN, Anterior lateral-line nerve; Ce, corpus cerebelli; D, degeneration; EG, eminentia granularis; HRP, horseradish peroxidase; PLLN, posterior lateral-line nerve; Va, valvula cerebelli

\begin{tabular}{|c|c|c|c|c|c|c|}
\hline Species & Literature & Nerve & Method & $\mathrm{EG}$ & $\mathrm{Ce}$ & $\mathrm{Va}$ \\
\hline \multicolumn{7}{|l|}{ Osteoglossomorpha } \\
\hline Gnathonemus petersii & $\begin{array}{l}\text { Maler et al. } 1973 \mathrm{~b} \\
\text { Maler et al. 1973a } \\
\text { Bell and Russel } 1978 \\
\text { Bell } 1981\end{array}$ & $\begin{array}{l}\text { ALLN } \\
\text { PLLN } \\
\text { PLLN } \\
\text { ALLN } \\
\text { PLLN }\end{array}$ & $\begin{array}{l}\text { D } \\
\text { D } \\
\text { HRP } \\
\text { HRP }\end{array}$ & $\begin{array}{l}+ \\
+ \\
+ \\
+ \\
+\end{array}$ & $\begin{array}{l}- \\
- \\
- \\
+ \\
+\end{array}$ & $\begin{array}{l}- \\
- \\
- \\
- \\
-\end{array}$ \\
\hline \multicolumn{7}{|l|}{ Elopomorpha } \\
\hline Anguilla anguilla & Meredith et al. 1987 & $\begin{array}{l}\text { ALLN } \\
\text { PLLN }\end{array}$ & HRP & $\begin{array}{l}+ \\
+\end{array}$ & - & $\begin{array}{l}- \\
-\end{array}$ \\
\hline
\end{tabular}

Euteleostei

Ostariophysi

Cyprinus carpio

Wallenberg 1907

PLLN

Luiten 1975

Carassius auratus

Zottoli and van Horne 1983

Puzdrowski 1989

ALLN D

PLLN

ALLN

PLLN

Finger and Tong 1984

ALLN

PLLN

Maler et al. 1974

ALLN

Apteronotus albifrons

Carr et al. 1982

PLLN

ALLN

$\mathrm{D}$
$\mathrm{D}$

HRP

HRP

HRP

HRP

HRP

D

D

HRP

ALLN HRP

Paracanthopterygii

Opsanus tau

De Rosa and Fine 1988

PLLN

HRP

Atherinomorpha

Mollienesia sphenops

Claas and Münz 1981

$\begin{array}{ll}\text { ALLN } & \text { HRP } \\ \text { PIIN } & \text { HRP }\end{array}$

Percomorpha

Lepomis cyanellus

Puzdrowski and Wullimann pers. obs.

ALLN

HRP

Astronotus ocellatus

Meredith 1984

ALLN

PLLN

McCormick 1983

ALLN

D, HRP

Crenicichla lepidota

Diaz and Anadon 1989

PLLN

HRP

ALLN

HRP

Chelon labrosus

this study

PLLN

D, HRP

ALLN

D, HRP

Macrognathus aculeatus

PLLN

HRP

HRP

$\begin{array}{lll}+ & - & - \\ + & - & - \\ + & + & - \\ + & - & - \\ + & + & - \\ + & - & - \\ + & - & - \\ + & - & - \\ + & - & - \\ + & - & -\end{array}$

or, alternatively, a piece of gelfoam soaked in this solution were applied to the cut end of one of the five relevant nerve trunks (see arrows in Fig. 1): either (1) the supraorbital (3 cases), (2) the maxillary ( 2 cases), (3) the mandibular (4 cases), (4) the hyomandibular nerve trunk ( 3 cases), or (5) the posterior lateral-line nerve (4 cases). Subsequently, the wound was sealed with Histoacryl (Braun, Melsungen, FRG). After 1-5 days, the spiny eels were re-anesthetized in MS 222 and transcardially perfused with cold $0.05 \mathrm{M}$ phosphate buffer (PB; pH 7.4) containing $0.8 \%$ sucrose, $0.4 \%$ glucose, and $0.8 \% \mathrm{NaCl}$, followed by $2 \%$ glutaraldehyde in $\mathrm{PB}$ containing $4 \%$ sucrose. The brains were removed from the crania and postfixed overnight in the same fixative. Thereafter, they were cryoprotected in $30 \%$ sucrose in PB and cut in the transverse plane on a cryostat, at a section thickness of $25 \mu \mathrm{m}$. The sections were reacted with benzidine dihydrochloride according to the protocol of Ebbesson et al. (1981) and counterstained with neutral ted.

\section{General anatomy}

One specimen of $M$. aculeatus was perfused as described above using $4 \%$ paraformaldehyde and decapitated; the whole head was postfixed for several months, and subsequently decalcified in titriplex (Merck, Darmstadt, FRG) for 20 days. It was embedded in paraffin, cut transversely at a section thickness of $15 \mu \mathrm{m}$ and silverstained with protargol (Merck, Darmstadt, FRG) according to the Bodian method (Romeis 1989) 


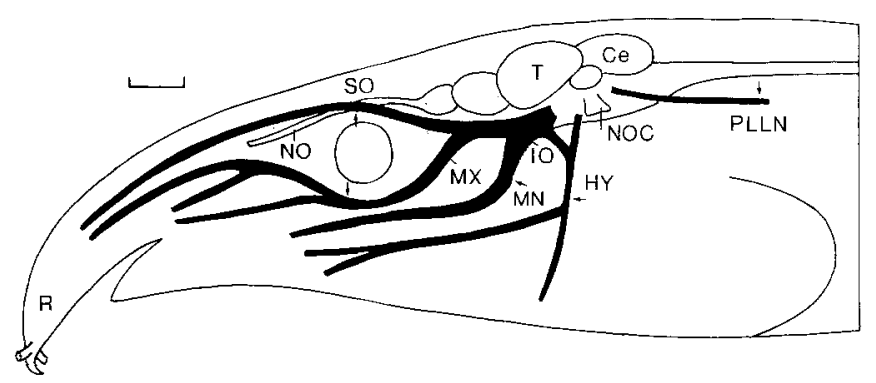

Fig. 1. Lateral view of the head of Macrognathus aculeatus showing the course of various cranial nerve trunks, some of which contain lateral-line components. Anterior lateral-line (including facial and trigeminal) nerves and the posterior lateral-line nerve are emphasized in black. The drawing summarizes data gained from dissections, from macerations and from a Bodian series of whole heads of $M$. aculeatus. Locations where HRP was applied to nerve trunks are indicated by arrows. Ce Corpus cerebelli; $H Y$ hyomandibular nerve trunk; $I O$ infraorbital nerve trunk; $M N$ mandibular nerve trunk; $M X$ maxillary nerve trunk; NO nervus olfactorius; $N O C$ nervus octavus; $P L L N$ posterior lateral-line nerve; $R$ rostrum; $S O$ supraorbital nerve trunk; $T$ tectum opticum; $V a$ valvula cerebelli. Bar: $1 \mathrm{~mm}$

\section{Macroscopic nerve preparations}

One specimen of $M$. aculeatus was perfused, as described above, using $5 \%$ formalin as the fixative. A second specimen was fixed by immersion in $5 \%$ formalin. The heads of these animals were then transferred to $30 \%$ nitric acid for 2-3 days, a procedure that macerates muscle tissue, but preserves nervous tissue. Two additional specimens were perfused as described above, using either AFA ( $90 \mathrm{ml} \mathrm{80 \%} \mathrm{ethanol;} 5 \mathrm{ml}$ formalin; $5 \mathrm{ml}$ glacial acetic acid) or $4 \%$ paraformaldehyde as the fixative, and dissected.

\section{Results}

\section{General anatomy}

Four heads of Macrognathus aculeatus were either dissected or macerated in order to reveal the distribution of nerve trunks carrying lateral-line fibers. Fig. 1 is a composite of data gained from these preparations. In addition, the Bodian series of an entire head of $M$. aculeatus was used to check the validity of the data.

As in the goldfish (Puzdrowski 1988), four cephalic nerve trunks, which carry trigeminal, facial and lateralline fibers, can be observed in the head of $M$. aculeatus: (1) a supraorbital nerve trunk and an infraorbital nerve trunk that branches off into (2) a maxillary and (3) a mandibular trunk; finally, (4) a hyomandibular nerve trunk is present. This level of observation does not reveal which cranial nerve components (trigeminal, facial and lateral-line) are contained in each of these trunks. However, an examination of the Bodian head series shows that there are three cephalic lateral-line canals: a supraorbital canal, an infraorbital canal, and a preoperculomandibular canal, as also seen in other teleosts (Northcutt 1989; Puzdrowski 1989; Webb 1989). Mechanoreceptors located in these three canals are innervated by lateral-line fibers running in the supraorbital, maxillary, and hyomandibular nerve trunks which correspond to the superficial ophthalmic and buccal rami of the anterodorsal lateral-line nerve, and to the external mandibular ramus of the anteroventral lateral-line nerve, respectively (Northcutt 1989; Puzdrowski 1989).

A posterior lateral-line nerve can be observed to innervate the lateral-line canal of the postcephalic body (Fig. 1). A middle lateral-line nerve (Northcutt 1989; Puzdrowski 1989) has not been observed in M. aculeatus.

\section{HRP experiments}

The medial octavolateralis nucleus was observed to receive terminals in all experiments, except for those in which we labeled the mandibular nerve trunk. All experiments resulted in the retrograde labeling of rhombencephalic efferent cells of the lateral-line system, again with the exception of the mandibular nerve trunk. In none of the five experiments could we observe diencephalic efferent neurons as described by Puzdrowski (1989). Here, we will focus on the lateral-line projections to different subdivisions of the cerebellum revealed by HRP application to the five nerve trunks noted above. A short summary of labeled facial and trigeminal nerve components is also given. All projections are ipsilateral, except for some contralateral trigeminal projections at the most caudal brainstem level to the medial funicular nucleus.

\section{Supraorbital nerve trunk}

After HRP application to the cut end of the supraorbital nerve trunk, fibers of the superficial ophthalmic ramus of the anterodorsal lateral-line nerve were labeled and could be observed to project massively to the granular layer of the ventral (and, less extensively, the dorsolateral) part of the valvula cerebelli throughout its rostrocaudal extent (Fig. 2a). In addition, weaker projections reached the rostroventral portion of the eminentia granularis (Fig. $3 \mathrm{a}, \mathrm{b}$ ).

\section{Maxillary nerve trunk}

After HRP application to the proximal stump of the maxillary nerve trunk, labeled fibers of the buccal ramus of the anterodorsal lateral-line nerve could be observed to project to the rostroventral part of the eminentia granularis. Massive projections also reached the granular layer of the ventral part of the valvula cerebelli (Fig. 2c) throughout its rostrocaudal extent.

\section{Mandibular nerve trunk}

After application of HRP to the cut end of the mandibular nerve trunk, a few labeled fibers of the anterodorsal lateral-line nerve could be observed to innervate the rostroventral eminentia granularis and a limited area within the granular layer of the ventral part of the valvula cerebelli, in one of four cases. 

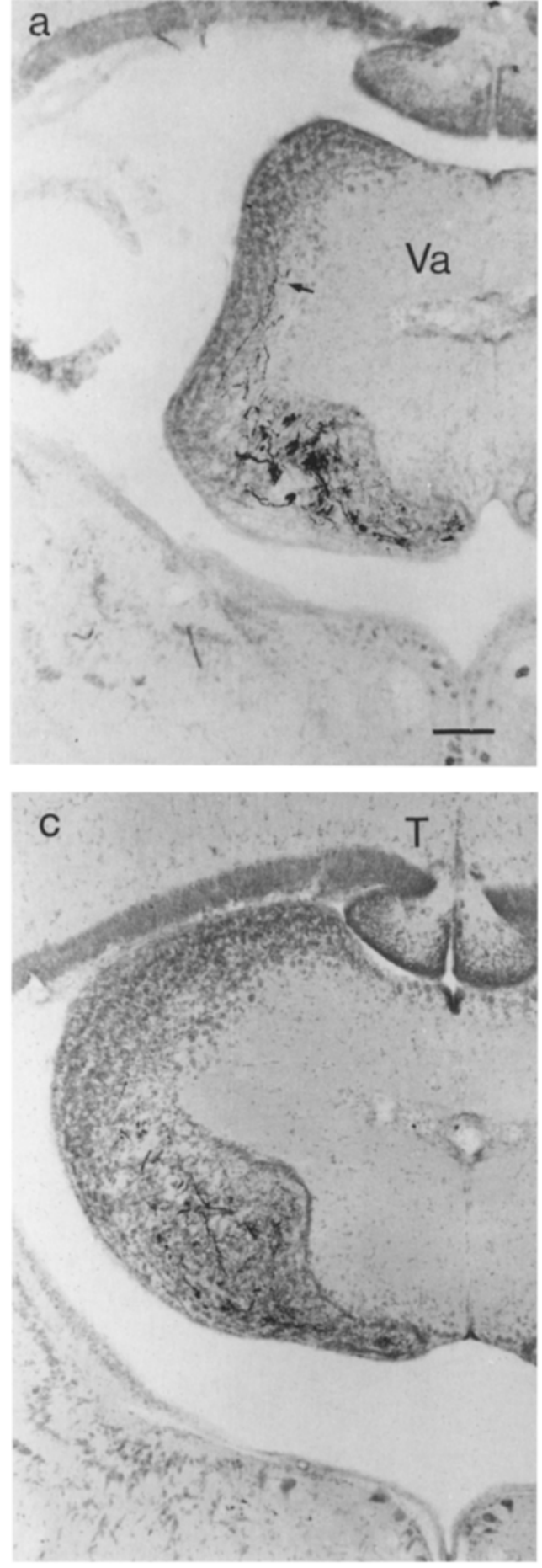
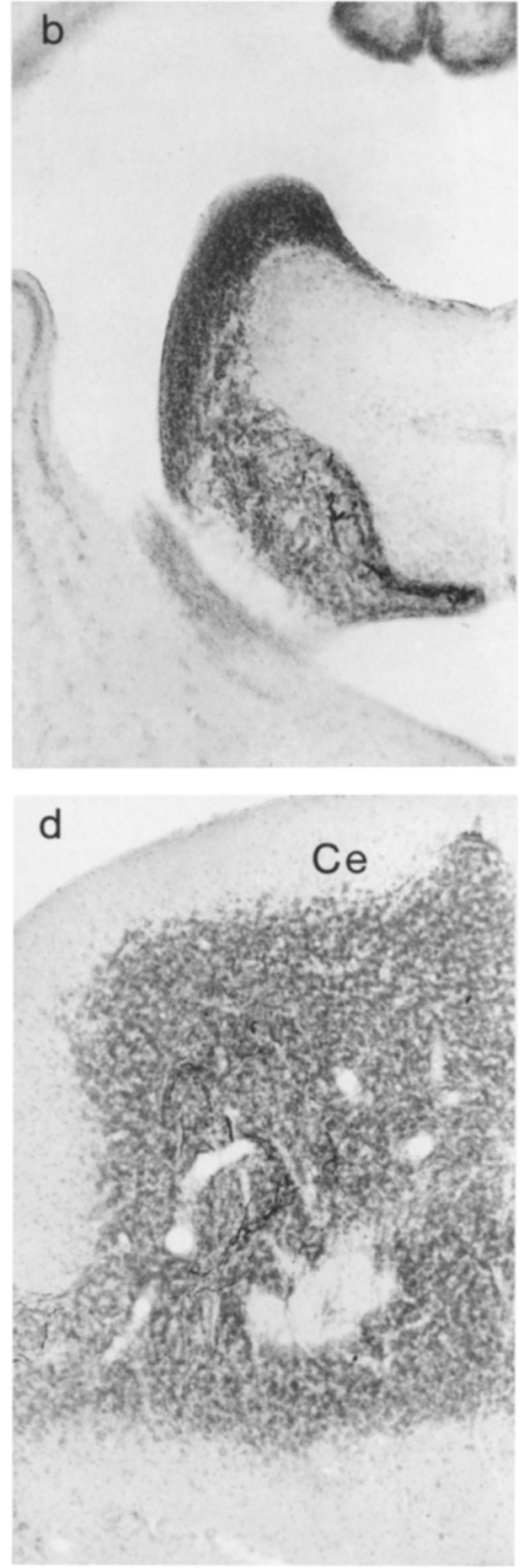

Fig. 2a-d. Photomicrographs of cross sections through the cerebellum in $M$. aculeatus showing terminals in the valvula after labeling of (a) the supraorbital nerve trunk, (b) the hyomandibular nerve trunk, and (c) the maxillary nerve trunk. Note that labeled fibers (arrow) reach the granular layer of the dorsolateral part of the valvula only in (a). d Terminals in the corpus cerebelli after labeling of the posterior lateral-line nerve. Lateral is to the left. Bar in a: $0.1 \mathrm{~mm}$ and applies to $\mathbf{b}-\mathbf{d}$

\section{Hyomandibular nerve trunk}

After application of HRP to the proximal stump of the hyomandibular nerve trunk, labeled fibers of the external mandibular ramus of the anteroventral lateral-line nerve were observed to project to the rostroventral eminentia granularis. Additional substantial projections reached the granular layer of ventral part of the valvula cerebelli (Fig. 2 b) throughout its rostrocaudal extent. Some fibers also reached the corpus cerebelli.

\section{Posterior lateral-line nerve}

After application of HRP to the cut end of the posterior lateral-line nerve, labeled fibers were observed to project 

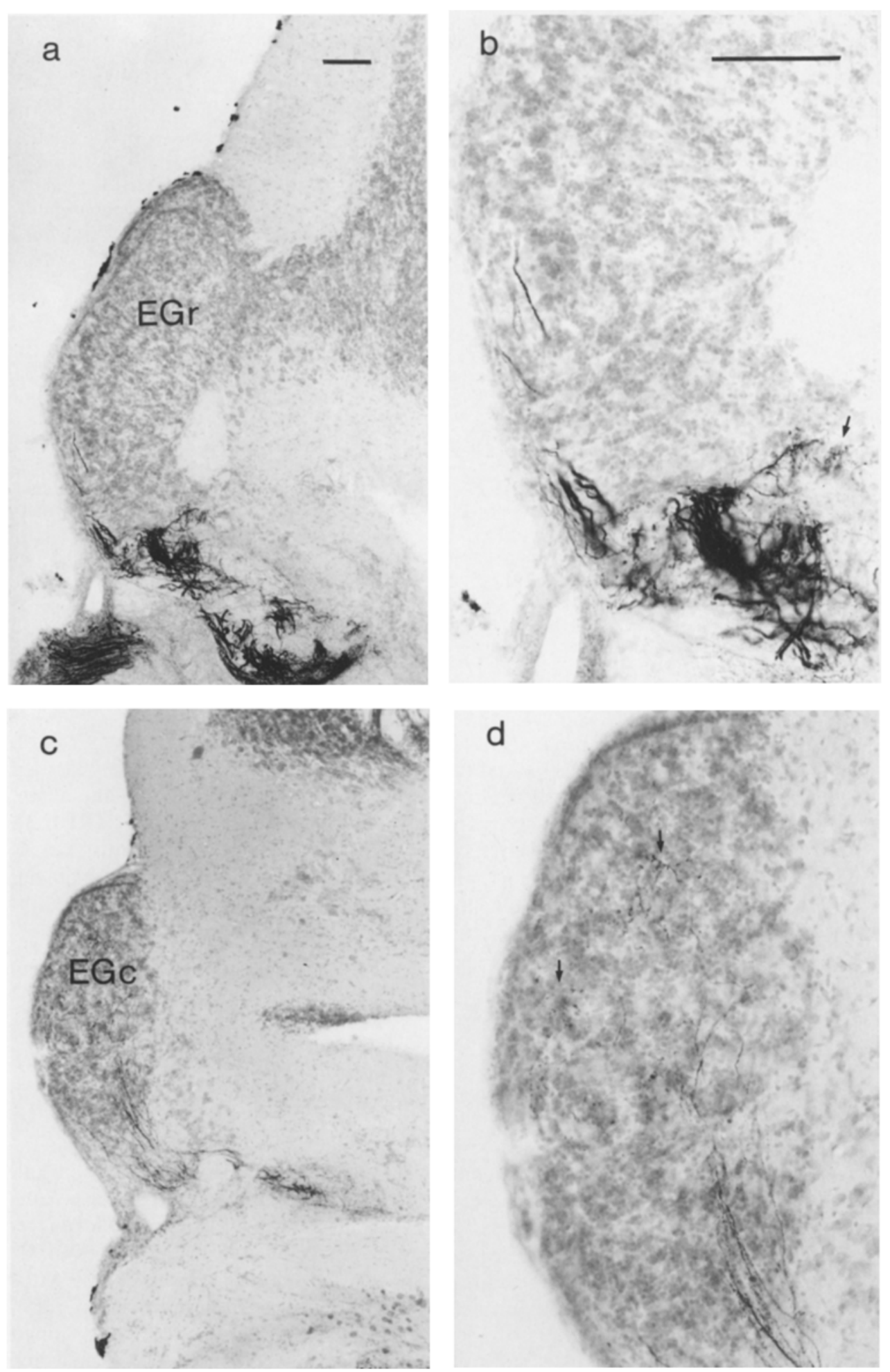

Fig. 3a-d. Photomicrographs of cross sections through the rostral $(\mathbf{a}, \mathbf{b} ; E G r)$ and caudal (c, d; $E G \mathcal{C}$ ) eminentia granularis in $M$. aculeatus after labeling of the supraorbital nerve trunk $(\mathbf{a}, \mathbf{b})$ or the posterior lateral-line nerve (c, d); $\mathbf{b}$ and $\mathbf{d}$ are enlargements of part of $\mathbf{a}$ and $\mathbf{c}$, respectively, to show the terminal arborization (arrows) of fibers. Lateral is to the left. Bars: $0.1 \mathrm{~mm}$; c, d same magnification as $\mathbf{a}, \mathbf{b}$, respectively extensively to the caudodorsal part of the eminentia granularis (Fig, 3c, d). Only a few fibers reached the most caudal part of the valvula cerebelli, whereas a substantial projection was seen to the corpus cerebelli (Fig. 2d).

\section{Facial and trigeminal components}

Table 2 summarizes these data schematically. Sensory facial and trigeminal projections were seen after labeling the supraorbital, maxillary, mandibular and hyomandi- 

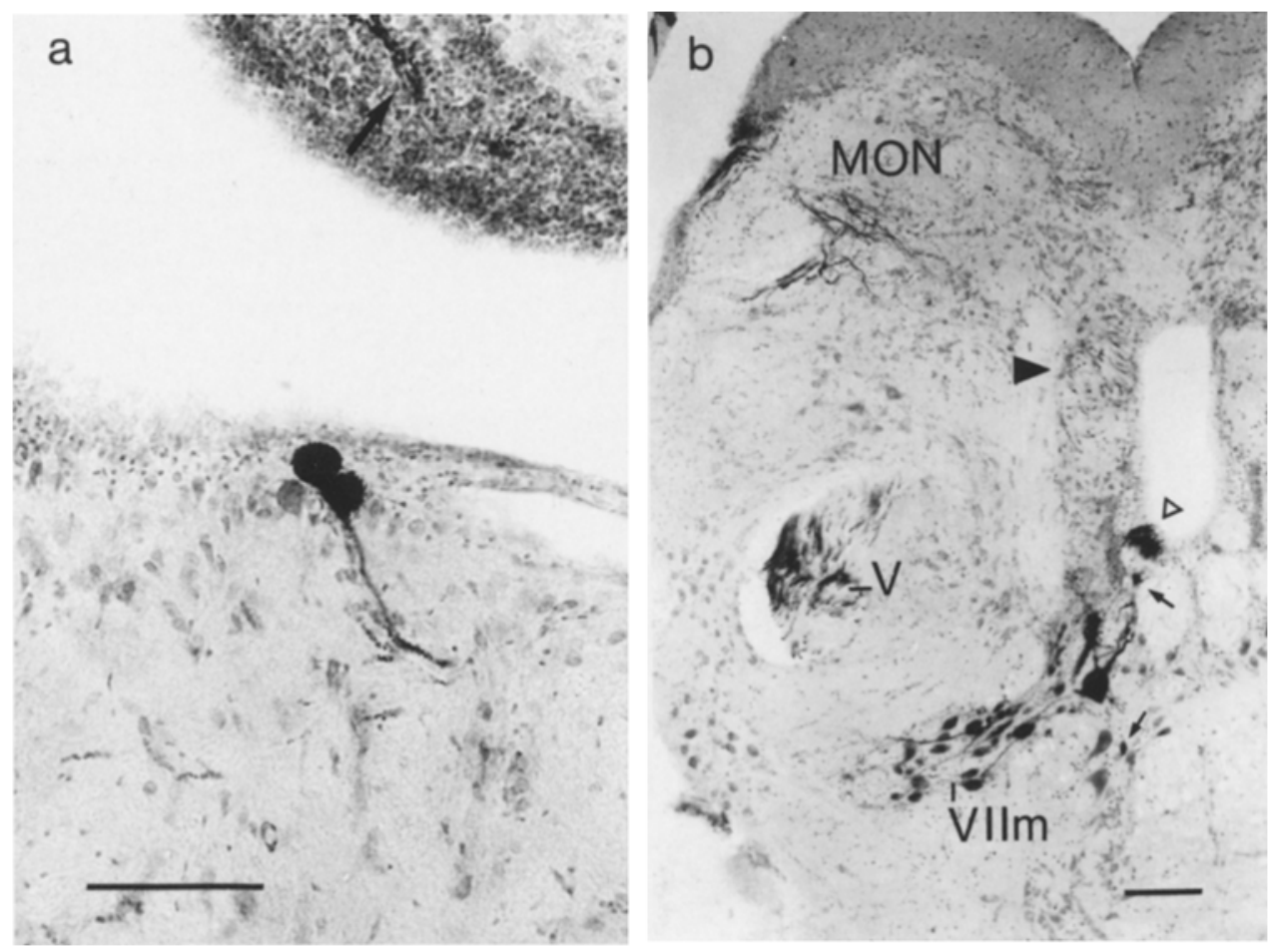

Fig. 4a, b. Photomicrographs of cross sections through the brain of $M$. aculeatus. a Labeled neurons of the mesencephalic trigeminal nucleus after HRP application to the maxillary nerve trunk Arrow points to labeled lateral line fibers in the rostral valvula. b Labeling of lateral line, trigeminal, and facial nerve components in the brainstem after HRP application to the hyomandibular nerve trunk. MON Medial octavolateralis nucleus; $V$ descending root of the trigeminal nerve; VIIm rostral facial motor nucleus. Arrowhead points to some labeled fibers in the sensory facial root; empty arrowhead points to the motor facial root; arrows point to efferent cells of the lateral line system. Lateral is to the left. Bars: $0.1 \mathrm{~mm}$

Table 2. Facial and trigeminal components labeled after HRP application to various cranial nerve trunks in Macrognathus aculeatus. HY, Hyomandibular nerve trunk; MES V, mesencephalic trigeminal nucleus; $\mathrm{V}$ sens, sensory trigeminal projections; $\mathrm{MN}$, mandibular nerve trunk; MX, maxillary nerve trunk; PLLN, posterior lateral line nerve; SO, supraorbital nerve trunk; VII sens, sensory facial projections; V mot, trigeminal motor nucleus; VII mot (r) and (c), rostral and caudal subdivisions, respectively, of facial motor nucleus; + , present; $-;$ absent. Only in last two columns: + , solid neuronal backfill of most neurons; $(+)$, granular backfill of some neurons

MES V V sens VII sens V mot VII mot

(r) (c)

\begin{tabular}{llllcll}
\hline $\mathrm{SO}$ & + & + & + & $(+)$ & - & - \\
$\mathrm{MX}$ & + & + & + & $(+)$ & $(+)$ & - \\
$\mathrm{MN}$ & + & + & + & + & - & - \\
$\mathrm{HY}$ & - & + & + & $(+)$ & + & + \\
$\mathrm{PLLN}$ & - & - & - & - & - & + \\
\hline
\end{tabular}

bular nerve trunks, but not after labeling the posterior lateral-line nerve. Neurons of the mesencephalic trigeminal nucleus were exclusively labeled after HRP application to the supraorbital, maxillary (Fig. 4a) and mandibular nerve trunks.

The trigeminal motor nucleus was massively labeled retrogradely (solid neuronal backfill in most neurons) after HRP application to the mandibular trunk. Lighter retrograde label (granular backfill) in some trigeminal motor neurons was also observed after HRP application to the three other cephalic nerve trunks.

Rostral and caudal subdivisions of the facial motor nucleus were massively labeled retrogradely after HRP application to the hyomandibular nerve trunk (Fig. 4b). The caudal facial motor nucleus was also heavily labeled after HRP application to the posterior lateral-line nerve. This was probably the result of a spread of HRP into muscular tissue, innervated by the facial motor nerve. Weaker (granular) retrograde label in the rostral facial motor nucleus was also seen after labeling of the maxillary nerve trunk.

\section{Discussion}

\section{Biological relevance of primary lateral-line projections to the cerebellum in mastacembeloids}

As expected from HRP-studies in other teleosts (see Table 1), all nerve trunks containing lateral-line fibers in Macrognathus aculeatus project to one part of the vestibulo-lateral lobe, the eminentia granularis. Moreover, fibers of anterior and posterior lateral-line nerves in $M$. aculeatus and in most other teleosts are segregated within the eminentia granularis (see Table 1 for references). Fibers of the anterior lateral-line nerves are positioned rostroventrally and fibers of the posterior lateral-line nerve are located caudodorsally.

The massive lateral-line projection to the granular layer of the valvula is only seen after labeling of the supraorbital, the maxillary, and, to a lesser degree, the hyomandibular nerve trunks. The small contingent of labeled fibers to the valvula noted after labeling the mandibular nerve trunk may be attributed to leakage of HRP to the maxillary nerve trunk, since labeling of the valvula is only seen in one of four cases. In all mandibular cases (unlike in the other experiments), there is no label in 


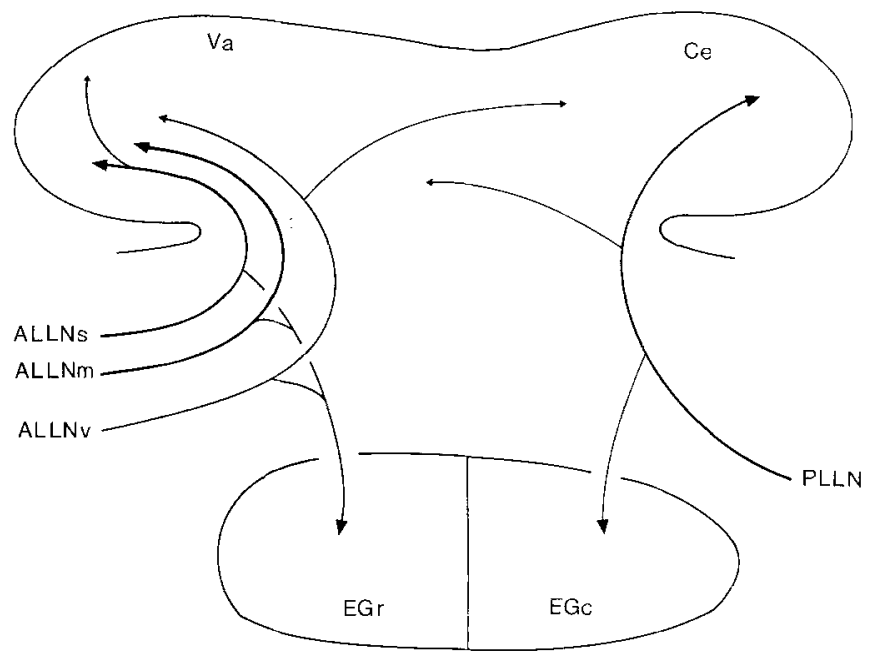

Fig. 5. Diagram summarizing primary lateral-line projections to the different parts of the cerebellum in Macrognathus aculeatus. $A L L N v$ Anteroventral lateral-line nerve fibers in the hyomandibular nerve trunk; $A L L N m$ anterodorsal lateral-line nerve fibers in the maxillary nerve trunk; $A L L N S$ anterodorsal lateral-line nerve fibers in the supraorbital nerve trunk; $C e$ corpus cerebelli; $E G c$ caudal eminentia granularis; $E G r$ rostral emimentia granularis; $P L L N$ posterior lateral-line nerve; $V a$ valvula cerebelli

the medial octavolateralis nucleus, which is the primary mechanosensory center in the brainstem. Furthermore, there is no retrograde label in efferent cells of the lateralline system. However, trigeminal and facial projections are well labeled in the mandibular cases. It may thus be concluded that (1) tactile and gustatory fibers are abundantly present in the mandibular nerve trunk, and that (2) mechanosensory fibers are probably absent. In descriptions of the cranial nerves and cephalic lateralline canals in another mastacembeloid species, Mastacembalus armatus, Maheshwari $(1965,1971)$ has also noted that only the supraorbital, maxillary and hyomandibular (but not the mandibular) nerve trunks innervate the three cephalic lateral-line canals.

Only a few fibers of the posterior lateral-line nerve reach the most caudal part of the valvula. Many posterior lateral-line nerve fibers project to the caudal portion of the eminentia granularis, and, even more, to the corpus cerebelli. A less extensive projection to the corpus also originates in the anteroventral lateral-line nerve, which innervates the lower jaw.

These results show that most mechanosensory information reaching the valvula stems from the rostrum of the upper jaw, since the latter is innervated by supraorbital and infraorbital nerve trunks. Furthermore, the mechanosensory information from the postcephalic body reaches the corpus, but not the main portions of the valvula cerebelli. This suggests an almost total spatial segregation of peripheral mechanosensory information within the cerebellum. The rostrum and rest of the head are represented in the valvula and rostroventral eminentia granularis, and the postcephalic body is represented in the corpus and caudodorsal eminentia granularis (Fig. 5). However, in the corpus, some mechanosensory information from the lower jaw runs in the anteroventral lateral-line nerve, and overlaps with that coming from the postcephalic body.

Of particular interest is the large projection to the valvula: this originates mostly from mechanoreceptors located in the highly specialized rostrum of spiny eels. The latter is mobile and may have a multimodal sensory function. It houses diverse sensory organs and their accessory structures, such as the rostral elongations of the supraorbital and infraorbital lateral-line canals, which extend to the tip of the rostrum. Moreover, the anterior nostrils are located at the tip of paired tubular extensions of the rostrum. Since our HRP applications to the supraorbital and infraorbital nerve trunks also labeled massive sensory projections of the facial and trigeminal nerves, gustation and somatosensory perception can be inferred to occur in the rostrum. There are other documented examples in teleosts where specialized appendages of the dorsal head region are innervated by facial and trigeminal sensory fibers (von Bartheld and Meyer 1985).

Further detailed histological investigations, currently underway, are aimed at the identification of sensory organs in the skin of the rostrum. Preliminary data show that complex (multicellular) sensory organs, which presumably represent free neuromasts, exist on the rostrum. The possibility that these organs are electroreceptors needs to be investigated. Nevertheless, these organs are not as abundant as would be expected if the massive projection to the valvula arises mostly from them. We therefore conclude that the canal neuromasts on the rostrum are the major source of the projection to the valvula, and thus, that mechanoreception is processed in this part of the cerebellum.

\section{Phylogenetic considerations}

In gnathostome vertebrates, primary octaval and, in species possessing lateral-line nerves, primary lateral-line projections to the vestibulo-lateral lobe of the cerebellum are universally present. This strongly suggests that these projections are an ancestral feature (plesiomorphy) of gnathostomes. In teleosts, the vestibulo-lateral lobe is represented by a paired eminentia granularis and the unpaired caudal lobe (Larsell 1967; Bass 1982). The former receives primary octaval (Bell 1981; McCormick 1983; Meredith and Butler 1983; Finger and Tong 1984; Meredith et al. 1987) and primary lateral-line information (see Table 1) in all teleost species investigated.

Early this century, descriptive anatomical evidence was presented that primary lateral-line projections reach the valvula in a number of teleost species, such as Gadus morrhua (Addison 1923), Ictalurus (=Ameiurus; Herrick 1924), Cyprinus carpio and two salmonid species (Pearson 1936b). However, such projections to the valvula were reportedly not seen in several other teleost species, such as Arius spec., Pleuronectes limanda (Addison 1923), Megalops cyprinioides (Van der Horst 1926), Silurus glanis, Mormyrus caschive (Berkelbach van der Sprenkel 1915), Carassius auratus (Pearson 1936a) and, con- 
trary to Herrick's report (1924), Ictalurus (=Ameiurus; Pearson 1936a). Nevertheless, the presence of primary lateral-line projections to the valvula in some euteleost species has been considered as evidence suggesting that the teleostean valvula represents part of the "evolutionarily old' vestibulo-cerebellum, and that the valvula is ancestrally related to the lateral-line and octaval systems, such as the remainder of the vestibulo-lateral lobe. An obvious alternative hypothesis that primary lateralline projections to the valvula are evolutionarily derived for some, but not all teleosts, has not been considered.

Recent studies (including the present one), using HRP and degeneration methods in more than a dozen species representing three of the four major teleost groups, have demonstrated primary lateral-line projections to the eminentia granularis and, in some species, to the corpus (Table 1). Of these 14 teleost species, massive primary lateral-line projections are reported to reach the valvula cerebelli only in the spiny eel (present study), and, to a lesser degree, in one additional euteleost, the black molly, Mollienesia (Claas and Münz 1981). This sheds new light on earlier interpretations of primary lateralline input to the valvula. Some of the older reports could be correct and may eventually be confirmed using modern tracers. Others, however, are unlikely to be supported by new evidence. Such is the case for the older studies on Ictalurus and Cyprinus, as HRP and degeneration studies exist within the same genus (Ictalurus; Finger and Tong 1984), or even the same species (Cyprinus carpio; Wallenberg 1907; Luiten 1975), and these experimental studies do not confirm primary lateral-line projections to the valvula. Unless one argues that, unlike the projections to eminentia granularis and corpus cerebelli, valvular projections cannot be visualized with HRP and degeneration methods, one has to assume that primary lateral-line projections are lacking in the majority of species investigated, and that they are only present in the two euteleost species in which they are visualized by HRP (although they may be present in some additional euteleost species that have been investigated by classical descriptive methods).

Thus, the new, experimental evidence suggests that primary lateral-line projections to the valvula represent a derived feature (autapomorphy) for some euteleosts and are not ancestral for teleosts. This interpretation is supported by evidence that primary lateral-line and octaval projections only reach the vestibulolateral lobe, but no other part of the cerebellum, in the non-teleost actinopterygians Amia (McCormick 1981), and Lepisosteus (Song and Northcutt 1991). Furthermore, in the cartilaginous fish Raja (Koester 1983; Barry 1987), which does not have a valvula, primary octaval and lateral line projections exclusively reach the vestibulolateral lobe and not the corpus cerebelli. The presence of primary lateral-line projections to the valvula cerebelli, in addition to such projections to the eminentia granularis and corpus cerebelli, in the shovelnose sturgeon Scaphirhynchus (New and Nortcutt 1984), can thus also be intepreted as an independently derived feature. This may be a case of parallel evolution since these sturgeons, similar to our spiny eels, also possess a rostrum.
In summary, the systematic distribution of primary lateral-line input to the valvula in teleosts (see Table 1) and other ray-finned fishes indicates that this character, rather than being ancestral, evolved three times independently: once in chondrosteans and twice in teleosts. This further appears to invalidate the hypothesis that the valvula cerebelli is ancestrally related to the octaval and lateral-line systems in the same way that the vestibulolateral lobe is. Our analysis is consistent with developmental (Pouwels 1978) and comparative anatomical (Nieuwenhuys 1967, 1982) data that suggest that the valvula is more closely associated with the corpus cerebelli, rather than with the vestibulolateral lobe. However, our hypothesis regarding the apomorphic nature of primary lateral line projections to the valvula in derived teleosts needs further testing, since only a limited number of species has been looked at experimentally.

Acknowledgements. We thank S. Kötting, S. Schmidt and K. Wullimann for expert technical assistance, J. Kirchhoff for introducing us to the nitric acid maceration-method, and Drs. B. Claas, H. Münz, R.G. Northcutt, and R.L. Puzdrowski for critically reading an earlier version of the manuscript and for offering insightful suggestions. This study was supported by the German Science Foundation (D.L.M.), the Swiss National Science Foundation, and the Janggen-Pöhn-Stiftung (M.F.W.).

\section{References}

Addison WHF (1923) A comparison of the cerebellar tracts in three teleosts. J Comp Neurol 36:1-35

Barry MA (1987) Afferent and efferent connections of the primary octaval nuclei in the clearnose skate, Raja eglanteria. J Comp Neurol 266:457-477

Bartheld CS von, Meyer DL (1985) Trigeminal and facial innervation of cirri in three teleost species. Cell Tissue Res 241:615-622

Bass AH (1982) Evolution of the vestibulolateral lobe of the cerebellum in electroreceptive and nonelectroreceptive teleosts. J Morphol 174:335-348

Bell CC (1981) Central distribution of octavolateral afferents and efferents in a teleost (Mormyridae). J Comp Neurol 195:391414

Bell CC, Russell CJ (1978) Termination of electroreceptor and mechanical lateral line afferents in the mormyrid acousticolateral area. J Comp Neurol 182:367-382

Berkelbach van der Sprenkel H (1915) The central relations of the cranial nerves in Silurus glanis and Mormyrus caschive. $\mathbf{J}$ Comp Neurol 25:5-63

Blübaum-Gronau E, Münz H (1987) Topological representation of primary afferents in various segments of the lateral line system in the butterflyfish, Pantodon buchholzi. Verh Dt Zool Ges $80: 268-269$

Carr CE, Maler L, Sas E (1982) Peripheral organization and central projections of the electrosensory nerves in gymnotiform fish. J Comp Neurol 211:139-153

Claas B, Münz H (1981) Projection of lateral line afferents in a teleost's brain. Neurosci Lett 23:287-290

De Rosa F, Fine ML (1988) Primary connections of the anterior and posterior lateral line nerves in the oyster toadfish. Brain Behav Evol 31:312-317

Diaz SM, Anadon R (1989) Central projections of the lateral line nerves of Chelon labrosus (teleosts, Order Perciformes). J Hirnforsch $30: 339-347$

Ebbesson SOE, Hansel M, Scheich H (1981) An 'on the slide' modification of the DeOlmos-Heimer HRP method. Neurosci Lett $22: 1-14$

Finger TE, Tong SL (1984) Central organization of eighth nerve 
and mechanosensory lateral line systems in the brainstem of ictalurid catfish. J Comp Neurol 229:129-151

Herrick CJ (1924) Origin and evolution of the cerebellum. Arch Neurol Psychiat 11:621-652

Koester DM (1983) Central projections of the octavolateralis nerves of the clearnose skate, Raja eglanteria. J Comp Neurol 221:199-215

Larsell $O(1967)$ The comparative anatomy and histology of the cerebellum from myxinoids through birds. University of Minnesota Press, Minneapolis

Luiten PGM (1975) The central projections of the trigeminal, facial and anterior lateral line nerves in the carp (Cyprinus carpio L.). J Comp Neurol 160:399-417

Maheshwari SC (1965) The cranial nerves of Mastacembelus armatus (Lacepede). Jpn J Ichthyol 12:89-98

Maheshwari SC (1971) The cephalic sensory canals of Mastacembelus armatus Lecepede. J Zool Soc India 23:163-166

Maler L, Karten HJ, Bennett MVL (1973a) The central connections of the posterior lateral tine nerve of Gnathonemus petersii. J Comp Neurol 151:57-66

Maler L, Karten HJ, Bennett MVL (1973b) The central connections of the anterior lateral line nerve of Gnathonemus petersii. J Comp Neurol 151:67-84

Maler L, Finger T, Karten HJ (1974) Differential projections of ordinary lateral line receptors and electroreceptors in the gymnotid fish, Apteronotus (Sternarchus) albifrons. J Comp Neurol 158:363-382

McCormick CA (1981) Central projections of the lateral line and eight nerves in the bowfin, Amia calva. J Comp Neurol 197:1-15

McCormick CA (1983) Central connections of the octavolateralis nerves in the pike cichlid, Crenicichla lepidota. Brain Res $265: 177-185$

Meredith GE (1984) Peripheral configuration and central projections of the lateral line system in Astronotus ocellatus (Cichlidae): a nonelectroreceptive teleost. J Comp Neurol 228:342358

Meredith GE, Butler AB (1983) Organization of eighth nerve afferent projections from individual endorgans of the inner ear in the teleost, Astronotus ocellatus. J Comp Neurol 220:44-62

Meredith GE, Roberts BL, Maslam S (1987) Distribution of afferent fibers in the brainstem from end organs in the ear and lateral line in the European eel. J Comp Neurol 265:507-520

New JG, Northcutt RG (1984) Central projections of the lateral line nerves in the shovelnose sturgeon. J Comp Neurol 225:129 140
Nieuwenhuys R (1967) Comparative anatomy of the cerebellum. Prog Brain Res $25: 1-93$

Nieuwenhuys $R$ (1982) An overview of the organization of the brain of actinopterygian fishes. Am Zool 22:287-310

Northcutt RG (1989) The phylogenetic distribution and innervation of craniate mechanoreceptive lateral lines. In: Coombs S, Görner P, Münz H (eds) Mechanosensory lateral line: neurobiology and evolution. Springer, Berlin Heidelberg New York, pp 17-78

Pearson AA (1936a) The acoustico-lateral nervous system in fishes. J Comp Neurol 64:235-273

Pearson AA (1936b) The acoustico-lateral centers and the cerebellum, with fiber connections, of fishes. J Comp Neurol 65:201294

Pouwels E (1978) On the development of the cerebellum of the trout, Salmo gairdneri. Anat Embryol 152:291-308

Puzdrowski RL (1988) Afferent projections of the trigeminal nerve in the goldfish, Carassius auratus. J Morphol 198:131-147

Puzdrowski RL (1989) Peripheral distribution and central projections of the lateral-line nerves in goldfish, Carassius auratus. Brain Behav Evol 34:110-131

Romeis B (1989) Mikroskopische Technik. Urban \& Schwarzenberg, München

Song J, Northcutt RG (1991) The primary projections of the lateral line nerves of the Florida gar, Lepisosteus platyrhincus. Brain Behav Evol 37:38-63

Van der Horst CJ (1926) The cerebellum of fishes. 2. The cerebellum of Megalops cyprinoides (Brouss.) and its connections. Konj Akad Wet (Amsterdam) Proc Sect Sci 29:44-53

Wallenberg A (1907) Beiträge zur Kenntnis des Gehirns der Teleostier und Selachier. Anat Anz 31:369-399

Webb JF (1989) Gross morphology and evolution of the mechanoreceptive lateral-line system in teleost fishes. Brain Behav Evol $33: 34-53$

Wullimann MF, Northcutt RG (1988) Connections of the corpus cerebelli in the green sunfish and the common goldfish: a comparison of perciform and cypriniform teleosts. Brain Behav Evol 32:293-316

Wullimann MF, Northcutt RG (1989) Afferent connections of the valvula cerebelli in two teleosts, the common goldfish and the green sunfish. J Comp Neurol 289:554-567

Zottoli SJ, Horne C van (1983) Posterior lateral line afferent and efferent pathways within the central nervous system of the goldfish with special reference to the Mauthner cell. J Comp Neurol 219:100-111 